Kiryoku, Volume 3 No 22019

e-ISSN: 2581-0960 p-ISSN: 2599-0497

Tersedia online di http://ejournal.undip.ac.id/index.php/kiryoku

\title{
VERBA KOMPON HAJIMERU, DASU, DAN KAKERU SEBAGAI PENANDA ASPEK INKOATIF BAHASA JEPANG
}

\author{
E.I.H.A. Nindia Rini \\ Universitas Diponegoro \\ Email: eliz_ikahesti@yahoo.co.id
}

\begin{abstract}
Abstrak
Baik verba kompon -hajimeru, -dasu, maupun -kakerudikenal sebagai penanda aspek inkoatif yang menyatakan dimulainya suatu aktivitas. Penelitian ini bertujuan mendeskripsikan struktur dan makna ketiga verba kompon tersebut agar dapat menggunakan ketiga penanda aspek ini dalam situasi yang tepat. Metode yang digunakan pada penelitian ini adalah metode deskriptif. Sebagai hasil penelitian ditemukanbahwa verba kompon -hajimeru merupakan penanda aspek inkoatif digunakan menyatakan mulainya suatu aktivitas atau peristiwa pada umumnya dalam bahasa Jepang; verba kompon -dasudigunakan untuk menyatakan dimulainya suatu aktivitas yang terjadi dengan tiba-tiba; sedangkan verba kompon -kakeru menyatakan sesaat akan dimulainya dan sesaat setelah dimulainya suatu aktivitas.
\end{abstract}

Kata kunci :verba kompon-hajimeru; verba kompon-dasu; verba kompon-kakeru; aspek inkoatif

\begin{abstract}
(Title: Compound Verbs -Hajimeru, -Dasu, -Kakeru as An Inchoative Aspects Marker in Japanese Language)Compound verb -hajimeru, -dasu, and-kakeruare known as marker of inchoative aspects that express the beginning of a state. This study aims to describe the structure and meaning of the three compound verbs in order to be able to use the three markers of this aspect in the right situation. The method used in this research is descriptive method. As a result of the study it was found that the compound verb-hajimeru compound were used to express the beginning of an activity or event in general in Japanese; compound verb-dasu is used to express the beginning of an activity that occurs suddenly; while the compound verb-kakeru states that activity will begin in a moment, or states a moment after an activity begin .
\end{abstract}

Keywords :compound verb; -hajimeru; -dasu; -kakeru; inchoative aspect marker

\section{PENDAHULUAN}

Aspek inkoatif adalah aspek yang memberikan penekanan pada segi permulaan keberlangsungan sebuah situasi (Tadjuddin, 2005:39).Pada bahasa Jepang aspek inkoatif ditandai secara gramatikal oleh verba kompon -hajimeru, -dasu, dan kakeru.

Penelitian terdahulu yang terkait dengan penelitian ini adalah skripsi Erlinda untuk menggambarkan hal yang terjadi secara bertahap. Perbedaan penelitian yang berjudul "Makna 'Mulai' pada Sufiks Dasu dan Hajimeru". Hasil penelitian ini menyimpulkan bahwa meskipun memiliki makna yang sama yaitu 'mulai', sufiks dasu dan hajimeru memiliki perbedaan. Sufiks dasu cenderung digunakan untuk menggambarkan hal yang tidak terduga, sedangkan sufiks hajimeru digunakan

penulis dengan penelitian terdahulu adalah bahwa penelitian penulis menambahkan 
verba sufiks kakeruuntuk melengkapi bahasan mengenai penanda aspek inkoatif bahasa Jepang.

Tujuan penelitian ini adalah untuk memaparkan struktur dan makna verba kompon -hajimeru, -dasu, dan -kakeru sebagai penanda aspek inkoatif agar dapat mengetahui karakteristik setiap penanda supaya dapat menggunakannya pada situasi yang tepat.

\section{METODE}

Penelitian ini merupakan sebuah studi kepustakaan dengan menghimpun informasi yang relevan dengan masalah yang diteliti dari buku-buku ilmiah, laporan penelitian, karangan-karangan ilmiah, ensiklopedia, dan sumber-sumber tertulis baik tercetak maupun elektronik lainnya

Hasil penelaahan lalu dipaparkan dengan metode deskriptif untuk membuat gambaran, lukisan secara sistematis, faktual dan akurat mengenai data, sifatsifat serta hubungan fenomena-fenomena yang diteliti (Djajasudarma, $2010: 9$ ).

\section{HASIL DAN PEMBAHASAN Verba Kompon}

Verba yaitu salah satu kelas kata dalam bahasa Jepang yang dipakai untuk menyatakan aktivitas, keberadaan, atau keadaan sesuatu. (Nomura dalam Sudjianto, 2012:149).

Verba kompon atau verba majemuk adalah verba yang terbentuk dari penggabungan verba pertama (zenkoudoushi) dengan verba kedua (koukoudoushi). (Masuoka et al, 1989:16). Penambahan verba kompon -hajimeru, dasu, dan -kakeru pada verba pertama menambahkan makna aspek inkoatif, yang memberi penekanan pada dimulainya suatu situasi.

\section{Verba Kompon -Hajimeru}

Menurut Iori (2001:92) verba kompon -hajimeru merupakan bentuk yang paling umum digunakan untuk menyatakan dimulainya sesuatu.Verba kompon-hajimeru dapat digunakan untuk menyatakan dimulainya sesuatu dengan subjekbenda mati (無生物 museibutsu), maupun fenomena fisiogis manusia (人間 の 生 理 現 象 ningen no seiri genshou).Selain itu, verba kompon hajimeru dapat pula berkonstruksi dengan verba yang menyatakan niat atau verba volisional (意志動詞 ishi doushi)seperti taberu 'makan', nomu 'minum', kau 'membeli', dan lain-lain,maupun yang tidak menyatakan niat atau verba non volisional (無意志動詞 muishi doushi), seperti kuzureru 'hancur', nagareru 'mengalir', naru 'menjadi', kawaru 'berubah', dan lain lain.

Hal ini sejalan dengan Hideo (1984 : 175), yang menyatakan juga bahwaditinjau dari segi niat pelaku, verba yang dapat melekatpada verba kompon -hajimeru ini adalah verba volisional maupun non volisional. Selain itu verba kompon hajimeru dapat berkonstruksi dengan verba intransitif (自動詞 jidoushi) maupun verba transitif (他動詞 tadoushi).Berikut ini adalah contohnya.

(1) 6 時から料理を作り始めよう。

(Iori, 2001:92)
Rokuji kara ryouri wo tsukurihajimeyou.

'Mari mulai memasak dari pukul 6.'

（2）昨日、レポートを書き始めた。

(Iori, 2001:92)

Sakujitsu, repooto wo kakihajimeta.

'Kemarin, (saya) mulai menulis laporan.

(3)まだ 5 時なのに暗くなり始めました ね。(Ichikawa, 2015:150)

Mada 5 ji na noni kurakunarimashitane.

'Padahal baru pukul 5, tetapi sudah mulai gelap ya.' 
Kiryoku, Volume 3 No 22019

e-ISSN: 2581-0960 p-ISSN: 2599-0497

Tersedia online di http://ejournal.undip.ac.id/index.php/kiryoku

(4) 雪が降り始めた。(Hideo, 1984:175)

Yuki ga furihajimeta.

'Salju mulai turun.'

Pada kalimat (1) verba volisional tsukuru 'membuat' melekat pada verba komponhajimeru yang berkonstruksi dengan modus yang menyatakan ajakan -you. Pelekatan verba kompon -hajimeyou di atas menunjukkan ajakan untuk mulai membuat masakan. Secara keseluruhan kalimat (1) menyatakan ajakan untuk mulai memasak dari pukul 6.Pada kalimat (2) verba volisional $k a k u$ 'menulis' melekat pada verba kompon -hajimeru yang berkonstruksi dengan kala yang menyatakan bentuk lampau -ta. Pelekatan verba kompon -hajimeta di atas menunjukkan mulainya aktivitas menulis laporan. Secara keseluruhan kalimat (2) menyatakan bahwa subjek mulai menulis laporan kemarin. Pada kalimat (3) verba nonvolisional kurakunaru' menjadi gelap' yang terbentuk dari adjektiva i kurai dan verba yang menyatakan perubahan naru, melekat pada verba kompon -hajimeru yang berkonstruksi dengan kala yang menyatakan bentuk lampau -ta. Pelekatan verba kompon -hajimeta di atas menunjukkan mulainya perubahan keadaan menjadi gelap. Secara keseluruhan kalimat (3) menyatakan mulainya perubahan subjekbenda mati (langit) yang dilesapkan menjadi gelap meskipun waktu baru menunjukkan pukul 5 sore. Pada kalimat (4) verba nonvolisional furu'turun' yang melekat pada verba kompon -hajimeru yang berkonstruksi dengan kala lampau - $t a$. Pelekatan verba kompon -hajimeta di atas menunjukkan mulainya fenomena alam turunnya salju.

Namun, verba kompon -hajimeru tidak dapat berkonstruksi dengan verba statif yang tidak memiliki titik awal yang jelas, seperti pada contoh berikut ini.

(5)*)最近、部屋にゴキブリがい始めた。
(Iori, 2001:92)

Saikin heya ni gokiburi ga ihajimeta.

Verba iru pada kata ihajimeta kalimat (5) merupakan verba statif yang tidak memiliki titik awal yang jelas, oleh karena itu kalimat(5) tidak berterima.

Kontruksi verba kompon -hajimeru pada verba perpindahan seperti (行くiku) 'pergi'akan menunjukkan dimulainya aktivitas yang terjadi secara berulangulang, seperti pada contoh di bawah ini.

(6)

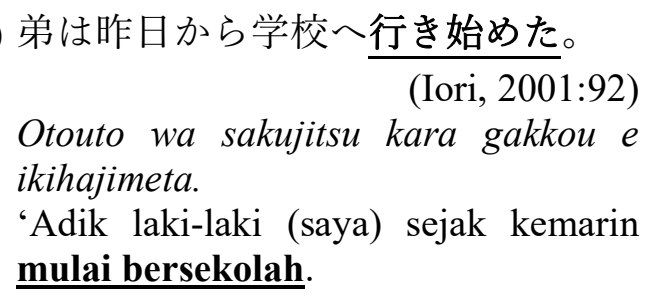

Pada kalimat (6) verba perpindahaniku melekat pada verba kompon -hajimeru yang berkonstruksi dengan kala yang menyatakan makna lampau -ta. Pada kalimat di atas kata ikihajimeta menyatakan dimulainya aktivitas pergi ke sekolah yang membutuhkan waktu panjang dan berulang-ulang sampai lulus.Secara keseluruhan kalimat (6) menyatakan dimulainya aktivitas adik bersekolah mulai kemarin.

Kato (1989:66) menambahkan bahwa verba kompon -hajimeru dapat juga dilekati verba pungtual ketika aktivitas tersebut terjadi berurutan dan membutuhkan waktu untuk selesai. Dalam hal ini aktivitas tunggal yang biasanya hanya membutuhkan waktu singkat, terjadi secara beruntun, dan verba kompon hajimeru menandai mulainya peristiwa yang dianggap secara keseluruhan sebagai sebuah fenomena, seperti pada contoh berikut ini.

(7) たった今、野鳥が飛び立ち始めた。

(Kato,1989:66)

Tatta ima, yachou ga tobihajimeja. 
'Baru saja, burung-burung liar mulai terbang.'

Pada kalimat (7) di atas, verba pungtual tobu 'terbang'dapat berkonstruksi dengan verba kompon -hajimeruyang melekat pada penanda kala lampau -ta, apabila subjek tidak tunggal.Secara keseluruhan kalimat (7) di atas menunjukkan mulainya peristiwa yachou 'burung liar' sebagai subjek yang tidak hanya satu (banyak) beterbangan.

\section{Verba Kompon -dasu}

Verba kompon -dasu merupakan bentuk yang juga menyatakan mulainya suatu aktivitas atau peristiwa. Verba kompon -dasu kerap digunakan dengan subjek benda mati, maupun fenomena fisiologis manusia. Nitta menyebutkan bahwa bahwa verba kompon -dasu lebih banyak digunakan untuk menunjukkan fenomena alam yang menimbulkan perubahan terjadi bukan berdasarkan niat seseorang (Nitta, 2007:37), seperti terlihat pada kalimat (8). Namun demikian, selain berkonstruksi dengan verba volisional, verba kompon -dasu dapat pula digunakan pada verba non volisional (Ichikawa, 2015:149). Selain itu menurut Iori, verba kompon -dasu umumnya digunakan untuk aktivitas atau peristiwa yang terjadi dengan tiba-tiba seperti terlihat pada contoh kalimat di bawah ini.

(8)雨が降り出した。(Iori, 2001:91)

Ame ga furidashita.

'Hujan mulai turun.'

(9)赤ちゃんが泣き出した。

Akachan ga nakidashita.

(Iori, 2001:91)

'Bayi mulai menangis.'

Pada kalimat (8) verba furu 'turun' melekat pada verba kompon -dasu yang berkonstruksi dengan kala lampau ta.Secara keseluruhan kalimat di atas menyatakan makna mulainya fenomena alam turunnya hujan.Pada kalimat (9) verba $n a k u$ 'menangis' melekat pada verba kompon -dasu.Secara keseluruhan kalimat (9) menyatakan makna aktivitas mulai menangisnya subjek bayi. Penggunaan verba kompon -dasu pada kalimat (8) dan (9) menyiratkan bahwa peristiwa 'mulai turun hujan' dan aktivitas 'mulai menangis' terjadi tiba-tiba.

Menurut Kato verba kompon dasutidak hanya dapat berkonstruksi dengan verba aktivitas saja, melainkan juga verba pungtual dengan ketentuan bahwa aktivitas atau perubahan terjadi dalam jangka waktu yang sama, sehingga aktivitas atau perubahan tersebut dilihat sebagai satu kesatuan proses. Misalnya pada contoh kalimat berikut ini.

(10)齐オン゙一つ一つ消えだした。

Neon ga hitotsu hitotsu kiedashita.

'Lampu neon mulai padam satu demi satu.'

Pada kalimat (10) verba pungtual kieru melekat pada verba kompon -dasuyang berkonstruksi dengan penanda kala lampau -ta.Penambahan verba kompon -dasu pada kalimat tersebut menunjukkan mulai padamnya lampu neon. Secara keseluruhan kalimat (10) menyatakan makna mulai padamnya lampu neon satu persatu (yang padam dalam jeda waktu yang sama).Kalimat di atas juga menyiratkan bahwa neon yang terdapat di tempat itu tidak hanya satu buah.

\section{Verba Kompon -kakeru}

Verba kompon -kakeru dapat berkonstruksi dengan verba pungtual (瞬間 動詞 shunkan doushi) maupun verba aktivitas (継続動詞 keizoku doushi).Verba kompon -kakeru digunakan untuk menunjukkan tahap sesaat sebelum aktivitas atau perubahan terjadi, atau tahap 
Kiryoku, Volume 3 No 22019

e-ISSN: 2581-0960 p-ISSN: 2599-0497

Tersedia online di http://ejournal.undip.ac.id/index.php/kiryoku

beberapa saat setelah aktivitas dimulai (Nitta, 2007:36). Verba kompon -kakeru muncul dalam beberapa bentuk, di antaranya -kakete iru, -kakete ita, -kaketa, dan -kake $+\mathrm{N}$.

Bentuk -kakete iru atau -kakete ita digunakan untuk menyatakan tahap sesaat sebelum aktivitas atau peristiwa benarbenar terjadi atau telah terjadi. Seperti pada contoh kalimat berikut ini.

(11)彼はビールを飲みかけていた。 (Iori, 2001:90)

Kare wa biiru wo nomikaketeita. 'Dia hampir meminum bir tadi.'

(12)「火事！」と聞いてビールを飲み かけていた彼は外に飛び出した。

(Iori, 2001:90)

"Kaji !" to kiite biiru wo

nomikaketeita kare wa soto ni tobidashita.

'Setelah mendengar ada yang berkata "Kebakaran !"dia yang hampir meminum bir, melompat keluar.'

Pada kalimat (11) verba aktivitasnomu 'minum' melekat pada verba kompon kakete ita pada kata nomikaketeita. Pelekatan verba kompon -kakete ita di atas, menunjukkan waktu sesaat sebelum aktivitas minum terjadi. Secara keseluruhan kalimat (11) menyatakan makna subjek 'dia' sebagai pelaku hampir meminum bir. Pada kalimat (12)verba aktivitasnomu 'minum' melekat pada verba kompon -kakete ita pada kata nomikaketeita. Pelekatan verba kompon kakete itadi atas, menunjukkan waktu sesaat sebelum aktivitas minum terjadi. Sehingga secara keseluruhan kalimat (12) menyatakan makna subjek 'dia' sebagai pelaku yang melompat keluar ketika mendengar teriakan "Kebakaran !" sesaat sebelum minum bir.

Tetapi Iori menyampaikan bahwa bentuk -kakete iru diinterpretasikan berbeda menurut jenis kata, dialek, maupun perbedaan persepsi setiap individu. Seperti terlihat pada kalimat berikut ini.

(13)雨が降りかけている。

(Iori, 2001:91)

Ame ga furikaketeiru.

(14)彼はご飯を食べかけている。

(Iori, 2001:91)

Kare wa gohan wo tabekaketeiru.

Menurut Iori, bagi penutur berdialek Tokyo, furikaketeiru pada kalimat (13) sulit diinterpetasikan sebagai 'Hujan turun.' (lebih tepat diinterpretasikan sebagai 'Hujan akan turun.'Tetapi bagi penutur berdialek Kyoto dan Osaka kalimat tersebut biasa diinterpretasikan (雨がすで に降っている) 'Hujan sudah mulai turun.' Sementara itu kata tabekaketeiru pada kalimat (14) ada penutur berdialek Tokyo yang menginterpretasikannya dengan ( す でに食べている) 'Sudah mulai makan.' Begitu pula penutur dialek Kyoto dan Osaka, yang biasa menginterpretasikan kalimat seperti di atas sebagai 'Sudah mulai makan.'

Pada bentuk -kaketa, verba kompon kakeru menunjukkan tahap mulainya peristiwa atau aktivitas, namun kemudian peristiwa atau aktivitas tersebut tidak jadi terjadi.Seperti terlihat pada kalimat di bawah ini.

(15)鈴木は何か言いかけたが、何も言 わなかった。(Nitta, 2007:36)

Suzuki wa nani ka iikaketaga, nanimo iwanakatta.

'Suzuki hampir mengatakan sesuatu tadi, tetapi tidak (jadi) mengatakan apa pun.'

(16)冒険家の田中は何度か死にかけた。

(Nitta, 2007:36) 
Boukenka no Tanaka wa nando ka shinikaketa.

'Sang petualang, Tanaka entah berapa kali hampir mati.'

Bentuk -kakeru pada kata iikaketa pada kalimat (15) menunjukkan tahap sesaat sebelum mengatakan sesuatu, namun akhirnya tidak jadi mengatakan apapun.Begitu pula shinikaketa pada kalimat (16) menunjukkan bahwa Tanaka sudah beberapa kali pun hampir mati, namun tidak jadi.

Moritamenambahkan bahwa verba kompon -kakeru digunakan terutama untuk menyatakan tahap sesaat sebelum suatu aktivitas terjadi, dan kembali pada keadaan semula. Berbeda dengan verba kompon kakaru yangdigunakan apabila tidak ada makna kembali ke kedaan semula nanti. Menurutnya, verba kompon -kakeru menyatakan bahwa suatu aktivitas atau peristiwa telah masuk pada tahap yang memiliki proses, pada tahap awalnya, sedangkan verba kompon -kakaru menyatakan situasi momentan telah mencapai satu titik sesaat sebelum tercapainya aktivitas.

(17) ろうそくが消えかけた。

(Morita, 1986:76)

Rousoku ga kiekaketa.

'Lilin hampir mati.'

(18)万うそくが消えかかった。

Rousoku ga kiekakatta.

(Morita, 1986:76)

'Lilin akan mati.'

Verba kompon -kaketa pada kata kiekaketa pada kalimat (17) menunjukkan lilin yang hampir mati, namun akhirnya tidak jadi mati, sedangkan verba kompon -kakatta pada kata kiekakatta kalimat (18) menunjukkan lilin yang akan mati, tanpa menyiratkan apakah lilin tersebut kembali ke posisi semula ataukah tidak,
Pada kalimat (19) di bawah ini verba aktivitas yomu 'membaca' melekat pada verba kompon -kaketa. Pada kalimat di bawah ini bisa diinterpretasikan bahwa subjek (saya) sebagai pelaku yang dilesapkan, hanya membuka buku saja tetapi tidak membacanya, atau telah membaca beberapa baris kalimat pada halaman pertama namun akhirnya berhenti.

(19)本を読みかけた。(Morita, 1986:72)

Hon wo yomikaketa.

'Mulai membaca.'

Pada kasus melekatnya verba pungtual pada verba kompon -kakeru, dengan subjek yang jamak, menunjukkan mulainya suatu aktivitas berkelanjutan dalam suatu jangka waktu tertentu.Misalnya pada kalimat di bawah ini.

(20)観客が立ちかけた。

Kankyaku ga tachikaketa.

(Morita, 1986:70)

'Para tamu mulai berdiri.'

Pada kalimat (20) verba pungtual tatsu 'berdiri' melekat pada verba kompon kaketa.Pada kalimat di atas ditunjukkan mulainya aktivitas berdirinya para tamu yang terus berlangsung sampai semua tamu dalam keadaan berdiri.

\section{Simpulan}

Berdasarkan penjelasan di atas dapat ditarik simpulan sebagai berikut.

1. Persamaan verba kompon -hajimeru, dasu, dan -kakeru adalah sebagai berikut :

1) Verba kompon -hajimeru, -dasu, dan -kakerusama-sama merupakan pemarkah aspek inkoatif yangmenyatakan dimulainya suatu aktivitas atau peristiwa. 
Kiryoku, Volume 3 No 22019

e-ISSN: 2581-0960 p-ISSN: 2599-0497

Tersedia online di http://ejournal.undip.ac.id/index.php/kiryoku

2) Verba kompon -hajimeru, -dasu, dan -kakerusama-sama dapat berkonstruksi dengan verba aktivitas.

3) Verba kompon -hajimeru, -dasu, dan -kakerusama-sama dapat digunakan untuk menyatakan aktivitas atau peristiwa dengan subjek benda mati, peristiwa alam, maupun subyek makhluk hidup.

2. Perbedaan verba kompon -hajimeru, dasu, dan -kakeru adalah sebagai berikut :

1) Verba kompon -kakeru dapat berkonstruksi dengan verba pungtual, sedangkan verba kompon -dasu, dan -hajimeru bisa berkonstruksi dengan verba pungtual hanya dengan subjek yang jamak dengan karakteristik aktivitas atau peristiwa yang terjadi berurutan.

2) Verba kompon -kakeru menununjukkan tahapan mulainya aktivitas atau peristiwa saja tanpa orientasi penyelesaian, sedangkan peristiwa -dasu, dan -hajimeru menyatakan mulainya suatu aktivitas atau peristiwa dengan orientasi penyelesaian.

3) Verba kompon -dasu digunakan untuk menyatakan mulainya suatu aktivitas atau peristiwa yang mulai dengan tiba-tiba, sehingga verba kompon -dasutidak dapat digunakan untuk menyatakan peristiwa yang terjadi secara perlahan seperti matahari terbenam. (×日が暮れだした。Hi ga kuredashita.)
Penelitian dan Kajian. Bandung : Refika Aditama.

Hideo, Teramura. (1984). Nihongo no Shintakusu to Imi Dai Ni Han. Tokyo: Kuroshio Shuppan.

Ichikawa, Yasuko. (2015). Chuukyuu Nihongo Bunpou to Oshiekata no Pointo. Tokyo :3A Corporation.

Iori, Isao. (2001). Atarashii Nihongo Nyuumon : Kotoba no Shikumi o Kangaeru. Tokyo : 3A Corporation.

Kato, Yasuhiko. (1989). Tensu, Asupekuto, Muudo. Tokyo: Aratake Shuppan.

Morita Yoshio, (1986). Kiso Nihongo : Imi to Tsukaikata. Tokyo : Kakuyou Shoten.

Nitta, Yoshio dkk. (2007). Gendai Nihongo Bunpou 3 : Asupekuto, Tensu, Kouhi. Tokyo : Kurushio Shuppan.

Sutedi, Dedi. (2011). Dasar-Dasar Linguistik Bahasa Jepang. Bandung: Humaniora

Sunarni, Nani dan Jonjon Johana. (2010). Morfologi Bahasa Jepang Sebuah Pengantar. Bandung : Sastra Unpad Press.

Tadjuddin, Moh. (2005). Aspektualitas dalam Kajian Linguistik. Bandung : PT Alumni.

http://www.lib.ui.ac.id/file?file=pdf/abstra k/id_abstrak-20413651.pdf [12/05/2019] 16:44

\section{DAFTAR PUSTAKA}

Djajasudarma, Fatimah. (2010). Metode Linguistik : Ancangan Metode 